\title{
Research Paper: Comparing Verb and Object Naming Between Patients With Parkinson Disease and Patients With Cortical Stroke
}

\author{
Zahra Mohamadi $^{1}$ (D), Nahid Jalilevand ${ }^{1 *}$ (D), Masoud Roudbari² ${ }^{\text {(D) }}$, Azar Mehri ${ }^{3}$ (D) \\ 1. Department of Speech Therapy, School of Rehabilitation Sciences, Iran University of Medical Sciences, Tehran, Iran. \\ 2. Department of Biostatistics, School of Public Health, Iran University of Medical Sciences, Tehran, Iran. \\ 3. Department of Speech Therapy, School of Rehabilitation, Tehran University of Medical Sciences, Tehran, Iran.
}

\begin{tabular}{|l|l|}
\hline $\begin{array}{c}\text { Use yourdevice to scan } \\
\text { and read the article online }\end{array}$ & $\begin{array}{l}\text { Cftation Mohamadi Z, Jalilevand N, Roudbari M, Mehri A. Comparing Verb and Object Naming Between Patients With } \\
\text { Parkinson Disease and Patients With Cortical Stroke. Iranian Rehabilitation Journal. 2018; 16(4):347-352. http://dx.doi. } \\
\text { org/10.32598/irj.16.4.347 }\end{array}$ \\
\hline dol http://dx.doi.org/10.32598/irj.16.4.347
\end{tabular}

(c) (i) (8)

Article info:

Received: 17 Apr 2018

Accepted: 13 Aug 2018

Available Online: 01 Dec 2018

\section{Keywords:}

Naming, Object naming, Parkinson Disease, Cortical stroke, Basal Ganglia

\section{ABSTRACT}

Objectives: Based on recent studies, verb naming is more impaired than noun naming in patients with Parkinson Disease (PD). Noun and verb retrieval problems has been well documented in patients with cortical damage. To explore the possible contribution of cortex and subcortex areas in word finding test performance, we studied verb and object naming in patients with cortical and subcortical lesions.

Methods: In this cross-sectional study, object and verb naming were examined in two patient groups, including patients with PD and patients with cortical stroke. The healthy control group was also matched on age and education with the patients. The non-parametric tests were performed to investigate the obtained data.

Results: Both the PD patients and patients with cortical stroke presented a significant impairment in their capacity to name objects and verbs, compared to the healthy controls $(\mathrm{P}<0.05)$. Both patient groups did not statistically perform differently on these tasks $(\mathrm{P}>0.05)$. There was also a significant difference between verb naming and object naming in both patient groups $(\mathrm{P}<0.001)$.

Discussion: The similarity between two patient groups and the difference between them and healthy individuals in language output, can denote the role of both cortical regions and basal ganglia in the language processing. 


\section{Highlights}

- We compared object naming and verb naming between Parkinson Disease (PD) patients, stroke patients, and normal people.

- Verb naming and object naming scores in the stroke patients were lower than those in PD group but this difference was not statistically significant.

- A significant difference between the normal and PD groups in language processing (noun and verb naming) was seen.

\section{Plain Language Summary}

The difference in verb and object naming between two groups of patients (PD patients and stroke patients) and healthy group can denote the role of both cortical regions and Basal Ganglia (BG) in the language processing.

\section{Introduction}

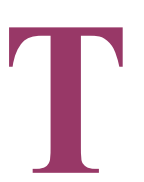

he role of Basal Ganglia (BG) in language processing has been investigated and debated since many years ago [1]. Parkinson Disease (PD) is a neurodegenerative disease caused by decreased dopamine in BG. The main PD motor symptoms, reported in many studies, are rigidity, bradykinesia, and tremor [2]. There are also non-motor symptoms including cognitive impairment and dementia [3], pain, sleep disorders, depression [4], executive function deficits [5], and language deficits [6].

Language impairment in PD includes spontaneous speech decline [7], sentence comprehension deficits [8], syntax comprehension impairments [9], and semantic deficits [10]. Many investigations have reported verb comprehension and verb production deficits in PD patients $[11,12]$. As a case in point, Contelli et al. studied action and object naming in patients with PD. They concluded that PD participants were significantly impaired in action naming and object naming [13]. Similarly, Fernandino et al. reported that patients with PD had more difficulties in action verbs processing than abstract verbs processing [14].

Different brain regions are involved in noun and verb processing. Specifically, noun deficits are related to lesions in the left anterior temporal region and verb deficits are related to the lesions in the left inferior frontal region [15]. According to Colman et al., language problems in PD patients are due to the cortico-striato-cortical circuits' degeneration [16]. Thus, it is supposed that verb processing deficit in PD is caused by the prefrontal network dysfunction [17]. Moreover, there is consider- able evidence of the disturbance of retrieving nouns and verbs after brain damage [18].

The connections between the BG and the cerebral cortex, particularly with the frontal lobe, have been argued in literature $[19,20]$. Cardona et al. proposed a motorlanguage network model in BG, composed of 2 major frontal and temporal subcomponents in action/verb processing [21]. Likewise, Macoir et al. concluded that the lower performance of PD patients in verb conjugation compared to the control group revealed the role of BG in language processing [22]. Furthermore, Cotelli et al. assessed memory, executive function, and verbal fluency in patients with PD. They reported deficiencies in both action and object naming in PD patients. They concluded that action naming impairment could be indicative of prefrontal dysfunction [13].

Rodríguez-Ferreiro et al. examined action and object naming in 2 patient groups including PD and Alzheimer's Disease (AD). They concluded that the AD participants were outperformed by the PD and control groups, and PD patients had naming impairment on both tasks, compared with the controls [23]. The current study evaluated noun and verb naming in 3 groups; patients with PD, patients with cortical stroke, and healthy individuals. We aimed to explore the potential differences in object naming and verb naming in patients with PD and patients with cortical stroke.

\section{Methods}

Twenty PD patients and 15 patients with cortical stroke and 20 healthy control participants, who matched with age and education level, participated in the present study. All the subjects were native Persian speakers, righthanded with normal vision (or corrected normal vision) 
and normal hearing. The control participants had no history of neurological and psychiatric disorders.

The patients were recruited from Hazrate-Rasule Akram Hospital and Rehabilitation Centers in Tehran City, Iran. The patients with PD had no history of other neurological and psychiatric disorders. They were evaluated using the Hoehn and Yahr (H \& Y) Scale [24]. They were medicated with levodopa and underwent medical assessments in the hospital. All of PD patients were on dopaminergic medication at the time of testing. Their Mean \pm SD, PD stage was $2.1 \pm 0.5$. Their cognitive performance was assessed using the Mini-Mental State Examination (MMSE) [25] to check the adequate cognitive function in participants. Their Mean \pm SD MMSE score was $26.9 \pm 1.58$. Language abilities were evaluated using the Persian version of the Western Aphasia Battery (WAB) [26]. Their Mean \pm SD WAB score was $88.01 \pm 9.89$.

The patients diagnosed with depression were excluded from the study. The minimum education level of patients was high school diploma. There were no significant differences between the patients with the cortical stroke and $\mathrm{PD}$ patients in the mean years of education $(\mathrm{P}=0.56)$. The patients with cortical stroke were in the chronic stage (2 to 11 years prior to their participation in this study) and were selected based on the CT scan or MRI reports. Inclusion criterion was cortical stroke without subcortical white matter damage. The participants with cortical stroke suffered from stroke to frontotemporoparietal, temporoparietal, frontotemporal, parietooccipital. Their Mean \pm SD WAB score was $83.13 \pm 20.84$. There were no significant differences in mean WAB scores between the patients with the cortical stroke and $\mathrm{PD}$ patients $(\mathrm{P}=0.88)$.

The Mean \pm SD age of the PD patients and patients with cortical stroke were $60.9 \pm 9.8$ and $52.2 \pm 10.9$ years, respectively. There were statistical differences in the mean age of the two groups of patients $(\mathrm{P}=0.01)$. Two different tasks were used for evaluating noun and verb naming in this study. The picture naming subtest of Persian Aphasia Battery [26], containing 50 pictures. The verb naming subtest of Persian Aphasia Battery with 50 pictures. All participants were assessed in convenient conditions (with minimum noise and enough light). Their answers were recorded using a digital voice recorder (KingstonDVR-902) [27].

\section{Statistical analysis}

In this cross-sectional study, statistical analysis was carried out using SPSS. The mean and standard deviation scores for age, duration of illness, MMSE, WAB, and naming tasks were calculated for each group. We conducted a Kolmogorov-Smirnov Test at $\mathrm{P}>0.05$ to assess normal distribution of data. Nonparametric tests were performed through Kruskal-Wallis test to compare the naming performance in the three groups. Mann-Whitney $U$ Test was used to compare the two groups; the correlation was analyzed by the Spearman's coefficient. Friedman test was conducted to compare 2 tasks in each group. The significance level was set at $\mathrm{P}<0.05$.

\section{Results}

Thirty-five patients (20 with PD and 15 with chronic cortical stroke) and 20 normal subjects (control group) participated in this study. The PD patients consisted of 4 (20\%) patients at H\&Y stage 1-1.5, 14 (70\%) patients at H\&Y stage 2-2.5 and $2(10 \%)$ patients at H\&Y stage 3. The patients with cortical stroke consisted of $6(35.7 \%)$ Right Hemisphere Damage (RHD) and 9 (64.3\%) Left Hemisphere Damage (LHD).

Table 1 lists the descriptive statistics of study variables. Analytical statistics were also calculated. The Spearman's coefficient suggested a positive correlation between object naming scores and verb naming scores in the the patients $(\rho=0.83, P=0.001)$. Similarly, Spearman's coefficient revealed a positive correlation between object naming scores and verb naming scores in the PD patients ( $\rho=0.53, P=0.01$ ). Moreover, the Kruskal-Wallis test suggested a significant difference between the patients and controls in the object naming scores $(\mathrm{P}=0.003)$ and verb naming scores $(\mathrm{P}=0.001)$.

The Mann-Whitney U Test indicated a significant difference between the patients with the cortical stroke and controls in object naming scores $(\mathrm{P}=0.001)$ and verb naming scores $(\mathrm{P}=0.001)$. Similar results were also obtained for the patients with PD and control group in object naming scores $(\mathrm{P}=0.001)$ and verb naming scores $(\mathrm{P}=0.001)$. However, the Mann-Whitney $\mathrm{U}$ test showed no significant differences between the two groups of patients in object naming scores $(\mathrm{P}>0.05)$ and verb naming scores $(\mathrm{P}>0.05)$. The Friedman test showed a significant difference between object naming scores and verb naming scores in the $\mathrm{PD}$ patients $(\mathrm{df}=1, \mathrm{P}=0.001)$, and patient with cortical stroke $(\mathrm{df}=1, \mathrm{P}=0.001)$.

\section{Discussion}

In the current study, we examined object naming and verb naming in the two groups of PD patients and patients with cortical stroke. Object and verb retrieval performances were the same in both patient groups, 
Table 1. The descriptive statistics of variables

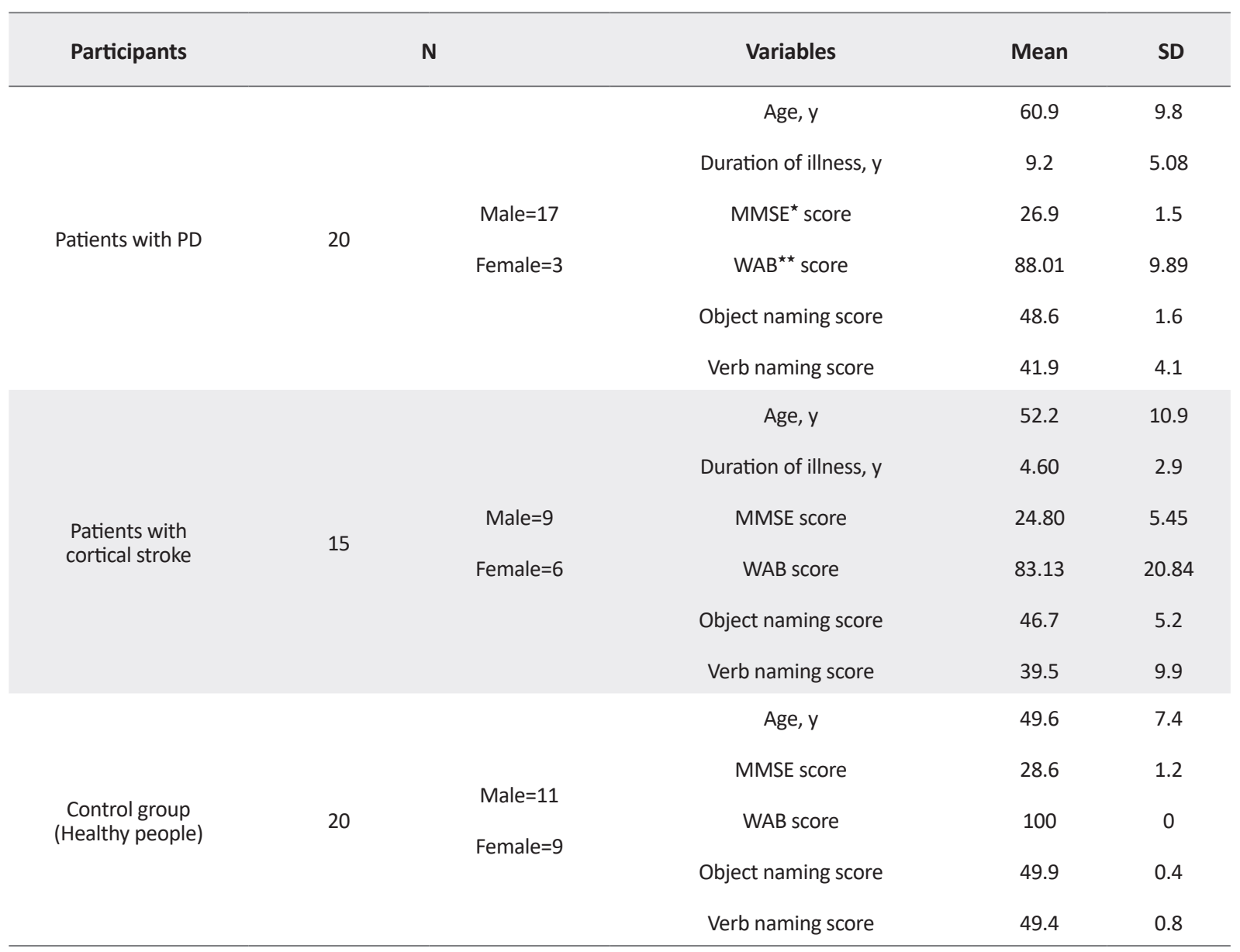

* Mini-Mental State Examination; ** Western Aphasia Test Battery

Iranian Rehabilitation Journa

and they were outperformed by the healthy controls on these tasks. Our findings revealed that the mean verb naming scores and object naming scores in the patient with cortical stroke were lower than that of PD group. However, this difference was not statistically significant. Rodríguez-Ferreiro et al. reported that the performance of $\mathrm{AD}$ group was lower than PD group in action and object naming tasks [23].

A positive correlation between object naming and verb naming scores in both patient groups manifested that with increasing the object naming scores, verb naming scores increase too. A similar impairment was observed in the patients with cortical stroke and those with neurodegenerative subcortical illness (Parkinson's disease), compared with the controls. This is the most important result of the current study, which can be an evidence for the role of both cortical and subcortical areas in language processing. In addition, there was a significant difference between the normal and PD groups in language processing (noun and verb naming), which highlights the role of dopaminergic pathways of BG and cortical areas in the language processing.

The same result was obtained for the patients with cortical stroke. The mean verb naming score was lower than the mean object naming score in both patient groups. Breedin et al. and Marshal et al. suggested that verb retrieval is more difficult than noun retrieval in aphasic patients $[28,29]$. Several surveys reported verb production deficits in PD patients as well [11-14].

According to Cardona et al. both BG and cortical regions are involved in action/verb processing [22]. Herrera et al. investigated verb naming performance in PD patients and concluded that the motor control area functionally could contribute to semantic processing of verbs [30]. There were some limitations to our research. First, because of the time limit, our study was conducted on a small size of patients. The low frequency of patients with cortical stroke without subcortical white matter damage was the second study limitation. 


\section{Conclusion}

The similarity between two patient groups (the cortical damage group and the PD group) in action and object naming, and the difference between them and the healthy group in the naming task, can denote the role of both cortical regions and $\mathrm{BG}$ in the language processing. Therefore, language processing requires normal cortical and subcortical functions.

\section{Ethical Considerations}

\section{Compliance with ethical guidelines}

This study was approved by the Iran University of Medical Sciences research ethics committee and Informed consent was obtained from all individual participants included in the study. The subjects voluntarily participated in this study and were allowed to withdraw as desired at any stage.

\section{Funding}

The Vice Chancellor for Research at Iran University of Medical Sciences supported this study.

\section{Authors contributions}

The authors contributions is as follows: Conceived of the study, formulated its design and data collection, drafted the manuscript, approval of the final version of the manuscript: Zahra Mohamadi; conducting the study, contributed in the conception of the work, assisted in interpreting the data, revising the draft, approval of the final version of the manuscript, and agreed for all aspects of the work: Nahid Jalilevand; performed the statistical analysis, approval of the final version of the manuscript, and agreed for all aspects of the work: Masoud Roudbari; and participated in the design of the study, approval of the final version of the manuscript, and agreed for all aspects of the work: Azar Mehri.

\section{Conflict of interest}

The authors declared no conflict of interest.

\section{Acknowledgements}

The authors are thankful to Mr. Ramin Mohseni for his contribution as the Speech and Language therapist in Hazrate Rasule Akram Hospital.

\section{Reference}

[1] Nadeau SE, Crosson B. Subcortical aphasia. Brain and Language. 1997; 58(3):355-402. [DOI:10.1006/brln.1997.1810] [PMID]

[2] Xia R, Mao ZH. Progression of motor symptoms in Parkinson's disease. Neuroscience Bulletin. 2012; 28(1):39-48. [DOI:10.1007/s12264-012-1050-z]

[3] Goldman JG, Litvan I. Mild cognitive impairment in Parkinson's disease. Minerva Medica. 2011; 102(6):441-52. [PMID] [PMCID]

[4] Chaudhuri KR, Healy DG, Schapira AH. Non-motor symptoms of Parkinson's disease: Diagnosis and management. The Lancet Neurology. 2006; 5(3):235-45. [DOI:10.1016/S14744422(06)70373-8]

[5] Parker KL, Lamichhane D, Caetano MS, Narayanan NS, Executive dysfunction in Parkinson's disease and timing deficits. Frontiers in Integrative Neuroscience. 2013; 7:75. [DOI:10.3389/fnint.2013.00075] [PMID] [PMCID]

[6] Lewis FM, Lapointe LL, Murdoch BE, Chenery HJ. Language impairment in Parkinson's disease. 1998; 12(3):193-206. [DOI:10.1080/02687039808249446]

[7] Liu L, Luo XG, Dy CL, Ren Y, Feng Y, Yu HM, et al. Characteristics of language impairment in Parkinson's disease and its influencing factors. Translational Neurodegeneration. 2015; 4(1):2. [DOI:10.1186/2047-9158-4-2] [PMID] [PMCID]

[8] Grossman M, Carvell S, Stern MB, Hurtig HI. Sentence comprehension in Parkinson's disease: The role of attention and memory. Brain and Language. 1992; 42(4):347-84. [DOI:10.1016/0093-934X(92)90074-O]

[9] Lieberman P, Friedman J, Feldman LS. Syntax comprehension deficits in Parkinson's disease. Journal of Nervous and Mental Disease. 1990; 178(6):360-5. [DOI:10.1097/00005053199006000-00003] [PMID]

[10] Portin R, Laatu S, Revonsuo A, Rinne UK. Impairment of semantic knowledge in Parkinson disease. Archives of Neurology. 2000; 57(9):1338-43. [DOI:10.1001/archneur.57.9.1338] [PMID]

[11] Colman KS, Koerts J, van Beilen M, Leenders KL, Post WJ, Bastiaanse R. The impact of executive functions on verb production in patients with Parkinson's disease. Cortex. 2009; 45(8):930-42. [DOI:10.1016/j.cortex.2008.12.010]

[12] Crescentini C, Mondolo F, Biasutti E, Shallice T. Supervisory and routine processes in noun and verb generation in nondemented patients with Parkinson's disease. Neuropsychologia. 2008; 46(2):434-47. [DOI:10.1016/j.neuropsycholoe gia.2007.08.021]

[13] Cotelli M, Borroni B, Manenti R, Zanetti M, Arévalo A, Cappa SF, et al. Action and object naming in Parkinson's disease without dementia. European Journal of Neurology. 2007; 14(6):632-7. [DOI:10.1111/j.1468-1331.2007.01797.x]

[14] Fernandino L, Conant LL, Binder JR, Blindauer K, Hiner B, Spangler K, et al. Parkinson's disease disrupts both automatic and controlled processing of action verbs. Brain and Language. 2013; 127(1):65-74. [DOI:10.1016/j.bandl.2012.07.008]

[15] Tyler LK, Bright P, Fletcher P, Stamatakis EA. Neural processing of nouns and verbs: The role of inflectional morphology. Neuropsychologia. 2004; 42(4):512-23. [DOI:10.1016/j. neuropsychologia.2003.10.001] [PMID] 
[16] Colman KS, Koerts J, Stowe L, Leenders K, Bastiaanse R. Sentence comprehension and its association with executive functions in patients with Parkinson's disease. Parkinson's Disease. 2011; 2011:213983. [DOI:10.4061/2011/213983]

[17] Péran P, Rascol O, Démonet JF, Celsis P, Nespoulous JL, Dubois $\mathrm{B}$, et al. Deficit of verb generation in nondemented patients with Parkinson's disease. Movement Disorders. 2003; 18(2):150-6. [DOI:10.1002/mds.10306]

[18] Damasio AR, Tranel D. Nouns and verbs are retrieved with differently distributed neural systems. Proceedings of the National Academy of Sciences. 1993; 90(11):4957-60. [DOI:10.1073/pnas.90.11.4957]

[19] Middleton FA, Strick PL. Basal-ganglia 'projections' to the prefrontal cortex of the primate. Cerebral Cortex. 2002; 12(9):926-35. [DOI:10.1093/cercor/12.9.926] [PMID]

[20] Ullman MT. Is Broca's area part of a basal ganglia Thalamocortical circuit? Cortex. 2006; 42(4):480-5. [DOI:10.1016/ S0010-9452(08)70382-4]

[21] Cardona JF, Gershanik O, Gelormini Lezama C, Houck AL, Cardona S, Kargieman L, et al. Action-verb processing in Parkinson's disease: New pathways for motor-language coupling. Brain Structure and Function. 2013; 218(6):1355-73. [DOI:10.1007/s00429-013-0510-1]

[22] Macoir J, Fossard M, Mérette C, Langlois M, Chantal S, Auclair Ouellet N. The role of basal ganglia in language production: Evidence from Parkinson's disease. Journal of Parkinson's disease. 2013; 3(3):393-97.

[23] Rodríguez Ferreiro J, Menéndez M, Ribacoba R, Cuetos F. Action naming is impaired in Parkinson disease patients. Neuropsychologia. 2009; 47(14):3271-4. [DOI:10.1016/j.neue ropsychologia.2009.07.007] [PMID]

[24] Hoehn MM, Yahr M. Parkinsonism: Onset, progression, and mortality. Neurology. 1967; 17(5):427-42. [DOI:10.1212/ WNL.50.2.318] [PMID]

[25] Ansari NN, Naghdi S, Hasson S, Valizadeh L, Jalaie S. Validation of a Mini-Mental State Examination (MMSE) for the Persian population: A pilot study. Applied Neuropsychology. 2010; 17(3):190-5. [DOI:10.1080/09084282.2010.499773]

[26] Nilipour R, Pourshahbaz A, Ghoreyshi ZS. Reliability and validity of bedside version of Persian WAB (P-WAB-1). Basic and Clinical Neuroscience. 2014; 5(4):253-8. [PMID] [PMCID]

[27] Mehri A, Ghaemi H, Kord N. [Providing a picture verb naming test and determine its validity in Persian aphasia patients (Persian)]. Journal of Modern Rehabilitation. 2009; 3(1):6-10.

[28] Breedin SD, Saffran EM, Schwartz MF. Semantic factors in verb retrieval: An effect of complexity. Brain and Language. 1998; 63(1):1-31. [DOI:10.1006/brln.1997.1923]

[29] Marshall J, Pring T, Chiat S. Verb retrieval and sentence production in aphasia. Brain and Language. 1998; 63(2):15983. [DOI:10.1006/brln.1998.1949]

[30] Herrera E, Rodríguez Ferreiro J, Cuetos F. The effect of motion content in action naming by Parkinson's disease patients. Cortex. 2012; 48(7):900-4. [DOI:10.1016/j.cortex.2010.12.007] 